Original Contribution

\title{
THE INFLUENCE OF TUITION INCREASE ON THE DESIRABILITY OF THE NURSING PROGRAM AT MEDICAL UNIVERSITY - PLOVDIV
}

\author{
R. Stoyanova*, S. Goranova \\ Medical University - Plovdiv, Plovdiv, Bulgaria
}

\begin{abstract}
Objective: The aim of the study is to determine how an increase in tuition can change the positive outcome of the sacrifice-gain assessment among nursing students at Medical University - Plovdiv. The study is limited to the negative effect of a higher tuition on the decision of students to drop the program. Methods: The study design is cross-sectional. An anonymous survey was carried out among 160 nursing students in March of 2016. The questionnaire contained items about the social and economic status of the respondent, demographics characteristic and the amount of tuition. Results were analyzed using descriptive statistics and non-parametric analysis.

Results: The majority of students consider the current tuition at Medical University- Plovdiv "too high", and only $23.1 \%$ find it "acceptable". An increase in excess of $30 \%$ of the tuition would lead to a drop of $68.8 \%$ or more in the percentage of students willing to continue their education at Medical University-Plovdiv. The percentage of possible transfer students is high in the case not only of freshmen, but of $3^{\text {rd }}$ year students as well. A worrisome fact is the high percentage of respondents $(n=26 ; 16 \%$ of the respondents) who, had they been able to turn back time, would not apply to our Nursing program.

Conclusion: The results of the survey serve as evidence for the existence of a breaking point, i.e. a level of tuition beyond which students are unwilling to continue their studies.
\end{abstract}

Key words: tuition, nursing students, nursing program, graduates, labor market.

\section{INTRODUCTION}

The medium remuneration level of a given profession influences not only the supply of workers in today's market, but in tomorrow's one well since the current level affects young people's choice of a university degree (1).

The positive correlation between the projected salary in a field and the number of applicants aspiring to study the corresponding university major certainly holds true for the area of Medicine. At Medical University - Plovdiv and in Bulgaria as a whole, this correlation is highly conspicuous in the case of Doctor Diplomas, whereas the expectation of a lower income is among the main factors for the decreasing popularity of Nursing degrees.

\footnotetext{
*Correspondence to: Rumyana Stoyanova, Department of Health Management and Health Economics, Faculty of Public Health, Medical University - Plovdiv, Bulgaria, 15A Vasil Aprilov Blvd., 4002Plovdiv, BULGARIA, 0035932602042, rumi_stoqnova@abv.bg
}

Of course, it is not a question of looking solely at the expected pay figure: young people compare that figure to the one of the cost of education. Again, it is not simply a cost: rather, it is the total cost that corresponds to various financial and other costs (among the latter one can count the length of study, the difficulty of the course, the need for acquiring additional skills, etc. ) (2). Thus, prospective students tend to compare the extent of certain sacrifice (expenses) to the one of potential gain. Their sacrifice is of three major types $(3,4,5)$ :

- $\quad$ personal expenses are living expenses, the cost of food and lodging and the like;

- cost of education includes mainly tuition, and to a much lesser extent - the cost of books and similar fees;

- loss of income addresses the income that could have been generated, had it not been for the full-time academic load.

Students' gain reflects their projected income, the possibility for professional growth and the 
low risk of unemployment after graduation (1, $2,6,7)$.

At the same time, the current high demand for qualified teaching personnel in the field of Medicine forces academic institutions to offer incentives to their teaching staff. The loom of an elevated turn-over rate is often kept at bay by offering more generous remunerations to teaching personnel, which in turn, typically translates into a tuition increase.

Our aim is to determine how, with all other factors remaining unaltered, an increase in tuition can change the positive outcome of the sacrifice-gain assessment. Our study is limited to the negative effect of a higher tuition on the number of Nursing students at Medical University-Plovdiv. We took into account only enrolled students (i.e. students that have already determined that their profession of choice has more pros than cons) in our attempt to track how much their tuition could be increased without causing a change in their initial decision and compelling them to drop the program.

\section{MATERIAL AND METHODS}

In March of 2016, anonymous questionnaires were filled out by 160 Nursing students in their $1^{\text {st }}, 2^{\text {nd }}$, and $3^{\text {rd }}$ year of study at Medical University -Plovdiv. Our Nursing program, just like all Nursing programs offered in Bulgaria, is state-regulated and the prescribed length of study is 4 years, thus we covered almost the whole spectrum of student types
STOYANOVA R., et al. (Freshman, Sophomore, Junior) save the one of $4^{\text {th }}$ year students (Senior).

The questions about the social and economic status of the respondent were closed, whereas the ones dealing with the age of the student and the amount of tuition he/she paid were open questions. The process question asked for students to consider at what percentage of tuition increase they would leave the university. The participating students represented $75 \%$ of the statistical population. The mean age of the respondents was 23.58 $\pm 6,459$. There were $41,2 \% \quad(n=66) 1^{\text {st }}$ year, $33,8 \%(\mathrm{n}=54) 2^{\text {nd }}$ year, and $25,0 \%(\mathrm{n}=40) 3^{\text {rd }}$ year students.

To analyze the collected data, we used SPSS 17 and Windows Excel, and relied on descriptive analysis, Pearson $\chi^{2}$ statistic, and correlation analysis.

\section{RESULTS}

We found out that all respondents enjoy statesubsidized tuition, which amounts to about 200 euro $(93.5 \%$ of the minimal Bulgarian salary in 2016). A significant number of the students, $53.1 \%(n=85)$, believe that even now this tuition is too high, having in mind the life standard in the country; $23.8 \%(n=38)$ cannot determine if it is so, whereas $23.1 \% \quad(n=37)$ consider their tuition "acceptable".

If the tuition is incremented by $30 \%$, the greater part of the students, $68.8 \%(\mathrm{n}=110)$, will leave the university. The answers can be grouped according to the year of study of the respondents (Table 1).

Table 1. Distribution of students' answers of the question: "At what percentage of tuition increase would you cease studying?"

\begin{tabular}{|c|c|c|c|c|c|c|c|c|}
\hline Kear of study & \multicolumn{2}{|c|}{$1^{\text {st }}$} & \multicolumn{2}{|c|}{$2^{\text {nd }}$} & \multicolumn{2}{|c|}{$3^{\text {rd }}$} & \multicolumn{2}{|c|}{ Total } \\
\hline $\begin{array}{l}\text { tuition increase would } \\
\text { you cease studying? }\end{array}$ & $\mathrm{n}$ & $\%$ & $\mathrm{n}$ & $\%$ & $\mathrm{n}$ & $\%$ & $\mathrm{n}$ & $\%$ \\
\hline$\leq 10 \%$ & 17 & 25,80 & 15 & 27,80 & 11 & 27,50 & 43 & 26,90 \\
\hline$\leq 20 \%$ & 16 & 24,20 & 14 & 25,90 & 5 & 12,50 & 35 & 21,90 \\
\hline$\leq 30 \%$ & 14 & 21,20 & 13 & 24,10 & 5 & 12,50 & 32 & 20,00 \\
\hline$\leq 40 \%$ & 5 & 7,60 & 2 & 3,70 & 2 & 5,00 & 9 & 5,60 \\
\hline$\leq 50 \%$ & 11 & 16,70 & 6 & 11,10 & 9 & 22,50 & 26 & 16,20 \\
\hline$\leq 60 \%$ & 0 & 0,00 & 2 & 3,70 & 0 & 0,00 & 2 & 1,20 \\
\hline$\leq 80 \%$ & 1 & 1,50 & 0 & 0,00 & 1 & 2,50 & 2 & 1,20 \\
\hline$\leq 100 \%$ & 2 & 3,00 & 2 & 3,70 & 7 & 17,50 & 11 & 6,90 \\
\hline Total & 66 & 100,00 & 54 & 100,00 & 40 & 100,00 & 160 & 100,00 \\
\hline
\end{tabular}

Our nonparametric analysis did not find significant statistical differences in the type of answers, based on the year of study of the respondents. A $30 \%$ tuition increase would serve as a deterrent even to $3^{\text {rd }}$ year-students, 
who are about to complete their course of study.

As expected, the respondents who believe that their tuition is already high, have a lower threshold of tuition increase tolerance $\left(\chi^{2}=\right.$ $45,372 ; \mathrm{P}=0,00 ; \mathrm{C}=0,470)$.

Typical of all students of Medicine, including Nursing students, is the very limited or practically non-existent possibility for them to work while pursuing a full course of studies, Hence students are not financially independent, and rely on financial assistance from their parents.

Our results completely concur with the above observation. Parents cover all the tuition and fees of $73,8 \% \quad(n=118)$ of the respondents. $17,5 \%(n=28)$ of them state to be financially self-sufficient, while $8,8 \% \quad(n=14)$ both work and receive financial assistance from their parents.
STOYANOVA R., et al. $31,9 \%(\mathrm{n}=51)$ of students live with their parents; $31,3 \% \quad(n=50)$ reside in student housing; 19,4\% $(\mathrm{n}=31)$ have an apartment of their own; 17,5\% $(n=28)$ rent an off-campus apartment.

It is important to note that neither the source of income during the course of studies, nor the type of housing, influences the critical level of tuition raise $(\mathrm{P}>0.05)$, i.e. the breaking point at which students give up studying. This demonstrates that students are conscious of the financial burden placed on their parents, and thus, even though this burden is usually not placed on the students themselves, they are still mindful of their tuition and its potential raise.

Also important is the number of students that graduate: it is less than $60 \%$ of the initially enrolled students. The history of our dropout rate shows that it is relatively stable. Figure 1 illustrates the relative stability of the ratio (1:1.5-1.6) between graduates and enrolled students over the period from 2008 to 2013.

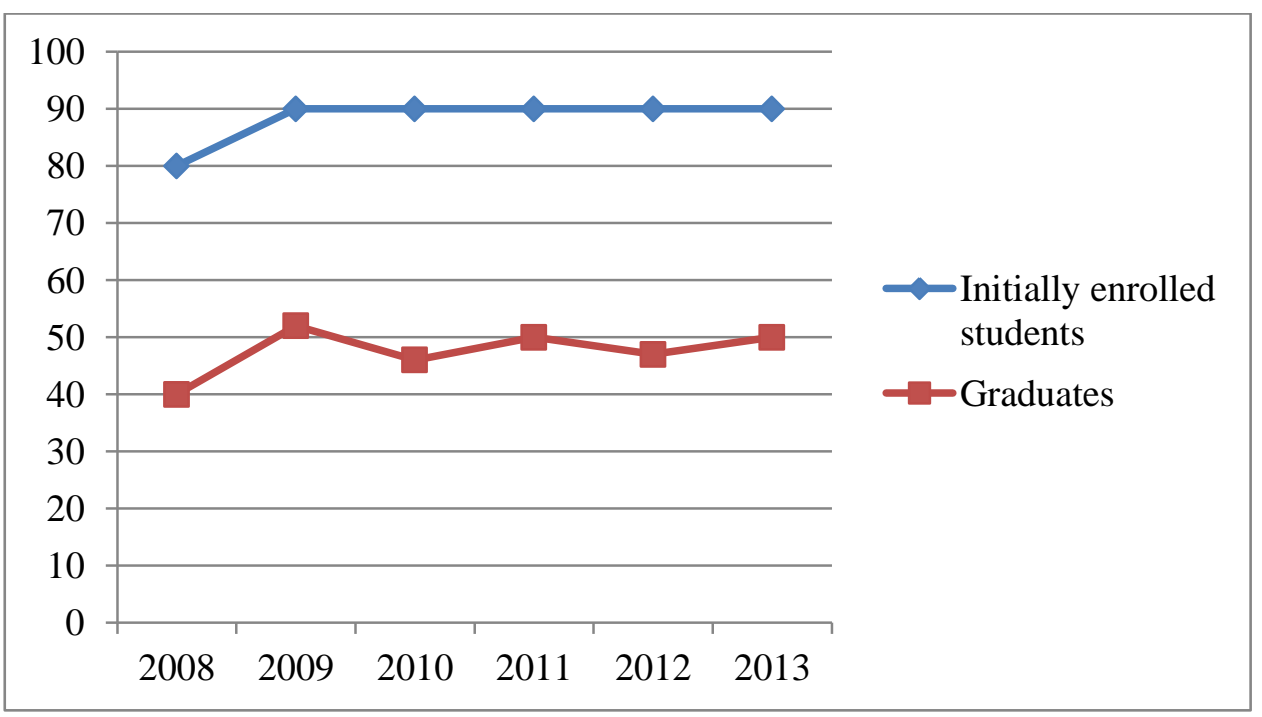

Figure 1. Total number of graduates and enrolled students at Medical University Plovdiv over the period from 2008 to 2013.

Our data shows a significant dropout rate. Even though the reasons behind it have not been researched in depth, we can spot a clear correlation between the $5.5 \%$ tuition raise (from about 190 euro tuition in 2008 to about 200 euros in 2013). Still, the existence of factors other than tuition should not be ignored. As mentioned above, aside from educational costs (such as tuition), there are personal expenses and loss of income that compete with expected gain. So, further research is needed to determine the exact extent of the influence of factors other than a prospective tuition raise.

\section{CONCLUSIONS}

In the context of a somewhat waning interest in Medical University-Plovdiv's Nursing program, it is crucial to identify the reasons for it. The results of our survey serve as evidence for the existence of a breaking point, i.e. a level of tuition beyond which students are unwilling to continue their studies. Still, further research is needed to determine the precise extent of the influence of tuition increase in the general panorama of factors that affect the outcome of the sacrifice-gain assessment. 


\section{REFERENCES}

1. Buerhaus, P., Auerbach, D. and Staiger, D., The recent surge in nurse employment: causes and implications. Health Aff, 28:w657-w668, 2009.

2. Card, D., The Causal Effect of Education on Earnings. In: Ashenfelter O and Card D (eds), Handbook of Labor Economics. Elsivier, pp 1801-1863, 1999.

3. Bruckmeier, K., Fischer, G., Wigger, B., Does Distance Matter. Tuition Fees and Enrollment of First-Year Students at German Public Universities. CESifoCESifo Working Paper, 4258, 2013.

4. Ke, X., The Willingness to Pay Tuition Fee at TH. Master of Science Thesis
STOYANOVA R., et al. 2012/140, KTH Industrial Engineering and Management, Stockholm, 2012.

5. Schwarz, S. and Rehburg, M., Study Costs and Direct public student support in 16 European countries-Towards a European higher education area? European Journal of Education, 39(4):521-532, 2004.

6. Alstadsæter, A., Measuring the consumption value of higher education. CESifo Economic Studies, 57(3):458-479, 2011.

7. Sá, F., The Effect of Tuition Fees on University Applications and Attendance:Evidence from the UK. Discussion Paper No. 8364, King's College London and IZA, 2014. 